\title{
AVALIAÇÃO DA BIODECOMPOSIÇÃO DE ÓLEO BRUTO E DIESEL ATRAVÉS DA PSEUDOMONA AERUGINOSA.
}

\author{
J. D. A. CÂMARA ${ }^{1}$, M. A. S. B. SOUSA ${ }^{1}$ e A. M. LIMA ${ }^{2}$ \\ ${ }^{1}$ Universidade Federal do Rio Grande do Norte, Departamento de Engenharia Química \\ ${ }^{2}$ Universidade Federal de Sergipe, Laboratório de Biotecnologia Ambiental \\ E-mail para contato: jessicacamara.eq@gmail.com
}

\begin{abstract}
RESUMO - Devido ao crescente uso de combustíveis fósseis, a contaminação do solo por hidrocarbonetos tem aumentado, provocando desequilíbrio ambiental. Esse estudo visa avaliar o potencial de biodegradabilidade do gênero Pseudomonas isoladas a partir de areia de filtro de piscina, em soluções contendo concentrações de óleo bruto e diesel. Foram utilizados microcosmos contaminados com quantidades conhecidas de óleo bruto (OB) e diesel (D), 2,50\% p/p, utilizando 2,00 kg de massa de solo, para determinação de sua capacidade de biorremediação com e sem a adição de bactérias. Os dados obtidos para remoção dos contaminantes foram 45,36 \% (OB) e 48,51 \% (D), nos ensaios sem adição de bactérias e de 63,50 \% (OB) e 75,47 \% (D) nos testes com adição de bactérias. Com os dados obtidos ao longo da pesquisa, foi possível concluir que o uso do grupo Pseudomonas isolados apresentaram resultados promissores em relação a capacidade de degradação para esses contaminantes em um curto intervalo de tempo.
\end{abstract}

\section{INTRODUÇÃO}

O crescente avanço da tecnologia vem demandando uma quantidade cada vez maior de recursos naturais, o que causa um desequilíbrio no meio ambiente, seja pelo uso indiscriminado ou pela introdução de produtos químicos em determinados locais. Um dos grandes problemas é o derramamento de petróleo e seus derivados, que têm contribuído para a contaminação do solo com hidrocarbonetos em todo planeta. Isso é causado principalmente pelas atividades de extração, transporte e refinamento. De acordo com Souza et al. (2010), observa-se que, os casos de contaminação do solo e água por hidrocarbonetos derivados de petróleo, que mesmo em pequenas concentrações podem constituir um grande perigo à saúde humana e ao meio ambiente.

Os métodos tradicionais, como a contenção e recolhimento através de barreiras flutuantes e a adsorção por materiais naturais ou sintéticos, não se apresentam como um método efetivo, pois estes não promovem a degradação do petróleo. A biorremediação, uma técnica natural, consiste na utilização de grupos microbianos capazes de degradar hidrocarbonetos. Esses microrganismos possuem a capacidade de biotransformar moléculas poluentes em nutrientes para a realização de suas funções metabólicas e fisiológicas.

A biorremediação baseia-se em três aspectos principais: a existência de microrganismos com capacidade catabólica para degradar o contaminante; a disponibilidade do contaminante ao ataque 


\section{9 a 22 de outubro de 2014 \\ Florianópolis/SC}

microbiano ou enzimático e condições ambientais adequadas para o crescimento e atividade do agente biorremediador. (Pereira e Lemos, 2005; Pasumarthi et al., 2013). Nesse sentido, uma das técnicas mais estudadas atualmente é a biodegradação, que utiliza grupos microbianos capazes de degradar hidrocarbonetos. Este método torna-se efetivo, uma vez que, o petróleo é usado como fonte de carbono através dos processos microbianos, resultando na quebra das moléculas em compostos de baixa massa molecular (Zang et al., 2005).

Porém, existe um fator que limita a biodegradação dos poluentes; segundo Kronemberg (2007) é a limitada disponibilidade destes compostos aos microrganismos, já que hidrocarbonetos geralmente se agregam aos componentes do solo, dificultando sua remoção ou degradação. E como a biorremediação de solos contaminados com resíduos oleosos depende da capacidade de assimilação desses compostos pelos microrganismos, há a necessidade da utilização de microrganismos que crescem na presença de contaminantes oleosos produzindo biossurfactantes.

A bioaumentação envolve a inoculação do solo com culturas puras ou consórcio microbiano contando microrganismos selecionados para degradação de contaminantes específicos. Esse processo tem sido estudado para vários herbicidas, hidrocarbonetos clorados e carbamatos através do emprego de populações nativas aclimatadas, isolados selecionados. Em geral, a bioaumentação é mais apropriada para tratamentos de contaminantes muito recalcitrantes, em contaminações recentes e onde se pretende aplicar a degradação acelerada (Moreira e Siqueira, 2002).

Uma das substâncias produzidas por microrganismos que utilizam o carbono presente nos derivados de petróleo e no óleo bruto é o biossurfactante, moléculas que possuem uma parte hidrofóbica e outra hidrofílica, provocando a separação de interfaces com diferentes graus de polaridade, tais como as interfaces óleo/água. Essa propriedade aumenta a solubilidade e a disponibilidade de poluentes hidrofóbicos aos microrganismos, aumentando o potencial de biodegradação.

Um dos compostos biossurfactantes mais investigados são os ramnolipídeos, produzidos pelo grupo Pseudomonas, nesse grupo a Pseudomona aeruginosa, bactéria Gram-negativa, pode ser isolada de diferentes habitats incluindo a água, o solo e plantas, é um patógeno oportunista humano que causa infecções nosocomial sérias e também é resistente a antibióticos. Sob condições ambientais específicas esta bactéria produz um biossurfactante contendo ramnose - glicolipídio. O tipo e a proporção do ramnolipídeo produzido dependem da cepa, da fonte de carbono utilizada e das condições de cultivo (Fontes et al., 2008).

O objetivo deste estudo é avaliar o potencial de biodegradabilidade do gênero Pseudomonas isoladas a partir de areia de filtro de piscina, em soluções contendo concentrações de óleo bruto (petróleo) e diesel.

\section{METODOLOGIA}

A amostra de petróleo utilizada foi coletada no campo de Fazenda Belém que localiza-se na porção noroeste da Bacia Potiguar emersa, leste do Estado do Ceará, nos municípios de Aracati, 
Icapuí e Jaguarana, cerca de $160 \mathrm{~km}$ a sudeste de Fortaleza. O material utilizado para desenvolvimento dos microrganismos foi areia de filtro de piscina de um condomínio residencial. Os experimentos foram conduzidos no Laboratório de Engenharia Ambiental e Controle de Qualidade no Departamento de Engenharia da Universidade Federal do Rio Grande do Norte LEACQ/DEQ/UFRN. O desenvolvimento desse estudo seguiu a sequência descrita no fluxograma apresentado na Figura 1.

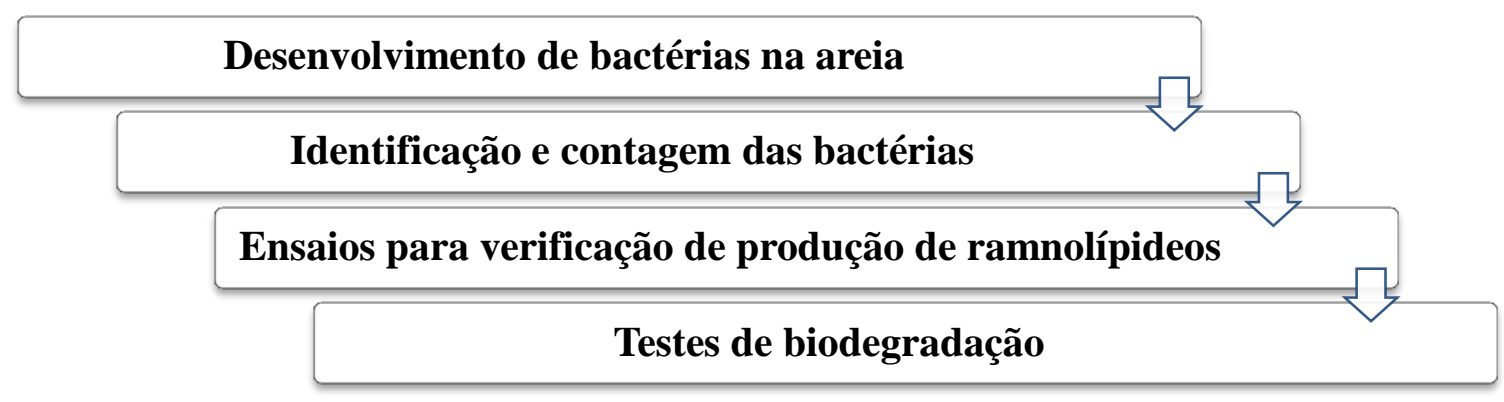

Figura 1 - Fluxograma das etapas adotadas no experimento.

\subsection{Desenvolvimento das bactérias}

As bactérias utilizadas nos ensaios de biodegradação foram obtidas através de um processo de adaptação em ambiente contaminado de forma controlada. Utilizou-se $1,50 \mathrm{~kg}$ de areia de filtro de piscina, a qual foi acondicionada em bandejas plásticas, e enriquecida com uma solução petróleo/diesel de 2,50 g. $\mathrm{L}^{-1}$, de modo que ficassem com uma concentração de $2 \% \mathrm{v} / \mathrm{m}$. $\mathrm{O}$ solo também foi umedecido com uma solução nutritiva com a seguinte composição: $\mathrm{KH}_{2} \mathrm{PO}_{4} 0,36 \mathrm{mg} . \mathrm{L}^{-1}$;

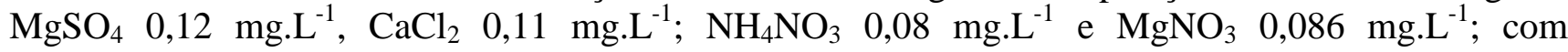
concentração idêntica a anterior: $2 \% \mathrm{v} / \mathrm{m}$. Durante 25 dias foi promovido, em intervalos regulares de cinco dias, a aeração e a exposição ao sol das bandejas que continham o solo. Nesse período, amostras de $1 \mathrm{~g}$ de areia foram recolhidas para as análises bacteriológicas para identificação e quantificação do gênero Pseudomonas.

\subsection{Identificação e quantificação bactérias}

Para identificação e quantificação utilizou-se erlenmeyers de $125 \mathrm{~mL}$ para acondicionamento de amostras de $1 \mathrm{~g}$ de areia diluídas em $100 \mathrm{~mL}$ de água destilada. Esse sistema foi submetido à agitação de 200 rpm por 24 horas. Após as 24 horas o líquido foi submetido a diluição seriada e inoculdas nos meios de cultura qualitativo Acetamide Agar e no quantitativo Cetrimide Agar, ambos meios seletivos para as Pseudomonas aeruginosa. Os meios de cultura com as amostras foram incubadas em estufa bacteriológica a $35{ }^{\circ} \mathrm{C}$ por $48 \mathrm{~h}$. Após a incubação foi realizada a contagem na placa de colônias formadas e o resultado expresso em Unidade Formadora de Colônia por mililitro de amostra (UFC/mL), de acordo com a Equação 1.

$$
U F C / m L=\frac{n^{0} \text { de colônicas }}{\text { fator de diluição da placa }}
$$




\section{9 a 22 de outubro de 2014 \\ Florianópolis/SC}

\subsection{Ensaios para verificação de produção de ramnolipídeos}

As colônias desenvolvidas foram repicadas e transferidas para um pré-inóculo com uma solução nutriente de peptona $2 \%$ em massa, onde permaneceram no shaker em agitação de $200 \mathrm{rpm}$ e $30{ }^{\circ} \mathrm{C}$ durante 24 horas.

Nos ensaios de fermentação utilizou-se como meio líquido para a avaliação da produção de biossurfactante e do crescimento celular, o meio mineral descrito por Robert et al. (1989), composto

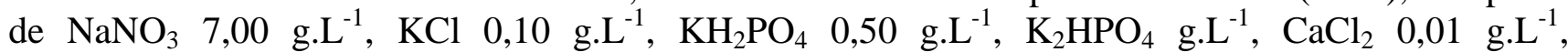
$\mathrm{MgSO}_{4} \cdot 7 \mathrm{H}_{2} \mathrm{O}$ 0,50 g.L ${ }^{-1}, \mathrm{FeSO}_{4} \cdot 7 \mathrm{H}_{2} \mathrm{O}$ 0,01 g.L ${ }^{-1}$, Extrato de levedura 0,10 g. $\mathrm{L}^{-1}$, utilizando glicerina como fonte de carbono nas concentrações de 2 e $10 \%$. Após ajuste de $\mathrm{pH}$ para 7,0, quando necessário, o meio de cultivo foi esterilizado a $121^{\circ} \mathrm{C}$ e 1 atm por 15 minutos.

Os ensaios de fermentação utilizou de $50 \mathrm{~mL}$ do meio descrito acima em erlenmeyers de 125 , inoculados com $1 \mathrm{~mL}$ do pré-inóculo (suspensão celular de Pseudomonas aeruginosa). Os erlenmeyers foram acondicionados em mesa agitadora, a $30^{\circ} \mathrm{C}$ e $200 \mathrm{rpm}$, mantidos durante 13 dias (312 horas), com amostragens realizadas a cada 2 horas nas primeiras 8 horas e depois a cada 24 horas para análise de crescimento celular, produção de ramnose.

A produção do ramnolipídeo foi quantificada através de análises colorimétrica em termos de concentração de ramnose produzida no meio de cultivo, através da análise de 6-deoxihexose (Chandrasekaran e Bemiller, 1980 apud Zang et al., 2005). O procedimento consiste em adicionar ao um tubo de ensaio adicionar $1 \mathrm{~mL}$ da amostra contendo ramnose juntamente com 4,50 mL da solução A $\left(90 \mathrm{~mL}\right.$ de $\left.\mathrm{H}_{2} \mathrm{SO}_{4}\right)$ e incubar por 10 minutos a $100^{\circ} \mathrm{C}$. Após a solução atingir a temperatura ambiente, adicionar $0,1 \mathrm{~mL}$ da solução $\mathrm{B}(0,2 \mathrm{~mL}$ de ácido tioglicólico e 5,8 $\mathrm{mL}$ de água destilada), homogeneizar os tubos e guardar em local com ausência de luz por três horas. Passado esse tempo, deve-se realizar a leitura de absorbância a $\lambda=400 \mathrm{~nm}$ e $\lambda=430 \mathrm{~nm}$ no espectrofotômetro UV visível. $\mathrm{Na}$ determinação da concentração de ramnose das amostras retiradas, $20 \mathrm{~mL}$ de cada amostra foram centrifugados por $40 \mathrm{~min}$ a $3500 \mathrm{rpm}$, separou-se o sobrenadante e a partir deste realizou-se o mesmo procedimento citado anteriormente. A equação foi utilizada para a conversão dos dados de absorbância à concentração equivalente.

\subsection{Ensaios de biodegradação}

O teste de acompanhamento do processo de biodegradação foi realizado em microcosmos (Figura 2) semelhantes aos utilizados na etapa de desenvolvimento das bactérias em solo. Nesse processo utilizou-se $2 \mathrm{~kg}$ de areia aplicando $50 \mathrm{~g}$ de cada contaminante (óleo bruto e diesel) simulando uma contaminação no ambiente, ocorrendo a mistura com o auxílio de bastão de vidro. Para cada hidrocarboneto foram utilizadas duas bandejas onde foram inoculados com $50 \mathrm{~mL}$ de caldo contendo Pseudomonas aeruginosa, utilizando a sequência de preparação de inóculo descrito no item 2.2 e um experimento sem a adição de microrganismo para cada contaminante. 


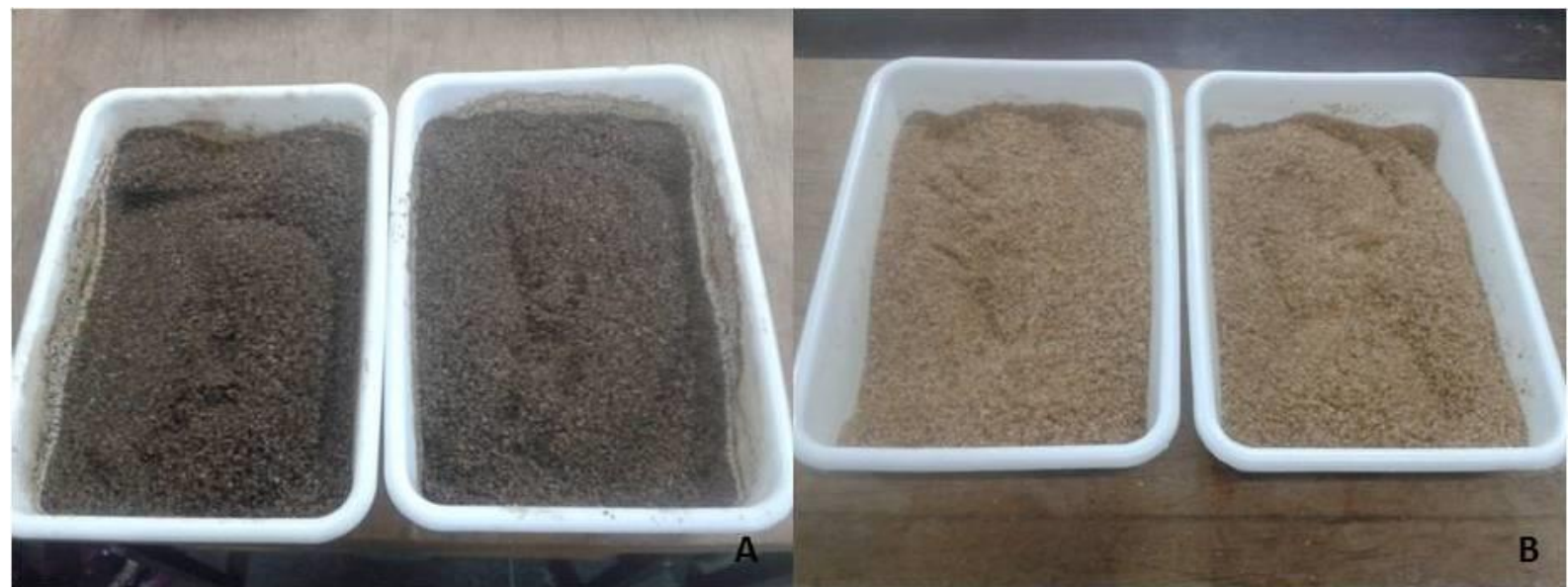

Figura 2 - Microcosmos utilizados para o ensaio de biorremediação. A) Contaminado com óleo bruto B) Contaminado com diesel.

Na avaliação da remoção de teor de óleo e graxas foram realizadas três amostragens ao longo de 28 dias. O teor de óleos e graxas (hidrocarbonetos) na areia durante o processo de biorremediação foi quantificado por método de extração contínua em aparelho tipo Soxhlet (Extrator de Óleos e Graxas Marconi MA-491) em 5 gramas de amostras. Os valores para os percentuais foram calculados pelas Eq. 2 e 3.

$$
\begin{aligned}
& \% O \& G=\frac{m_{\text {óleo }}}{m_{\text {amostra }}} * 100 \\
& \% R O \& G=\left(1-\left(\frac{C_{f}}{C_{i}}\right)\right) * 100
\end{aligned}
$$

Onde:

$\% \mathrm{O} \& \mathrm{G}-\quad$ porcentagem de óleos e graxas;

$\mathrm{m}-\quad$ massa em gramas $(\mathrm{g})$;

\%RO\&G - porcentagem de remoção de óleos e graxas;

$\mathrm{C}_{\mathrm{f}}-\quad$ percentual de óleos e graxas da amostra no tempo final de biorremediação;

$\mathrm{C}_{\mathrm{i}}-\quad$ percentual de óleos e graxas da amostra no tempo inicial de biorremediação

\section{RESULTADOS E DISCUSSÕES}

\subsection{Acompanhamento do desenvolvimento de Pseudomonas no solo}

Durante 25 dias foi analisado, tanto quantitativamente como qualitativamente, a presença de bactérias do tipo Pseudomona aeruginosa em solo contaminado manualmente. O resultado pode ser observado na Figura 3. 


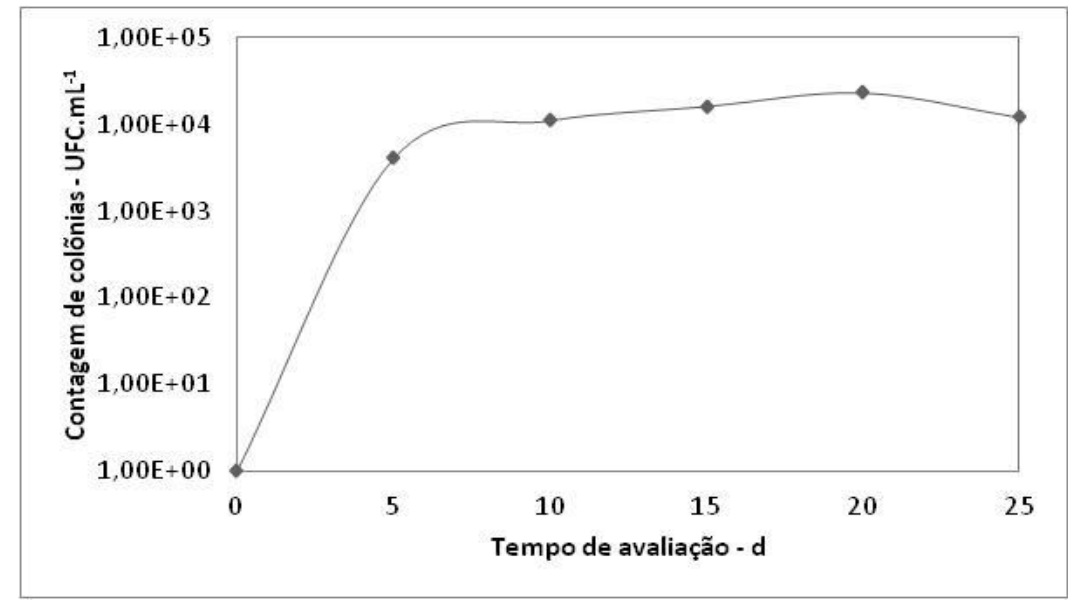

Figura 3 - Quantificação das bactérias desenvolvidas na areia contaminada com petróleo/diesel.

Pode-se observar que ocorreu um crescimento da quantidade de colônias ativas até o vigésimo dia. Portanto, apenas durante o período de desenvolvimento das bactérias é que as colônias foram repicadas e preservadas.

\subsection{Avaliação da produção de biossurfactante}

Ao analisar a produção de biossurfactante durante o crescimento em glicerina, nas duas concentrações estudadas, observou-se uma baixa produção do tensoativo em baixas concentrações de carbono. Utilizando a concentração $2 \%$ de glicerina houve um pico de $5,14 \mathrm{mg} . \mathrm{L}^{-1}$ de ramnose no tempo de $72 \mathrm{~h}$, seguido pelo decaimento da sua concentração, o que pode indicar um provável consumo do produto por parte da bactéria quando o substrato passou a ter concentrações reduzidas.

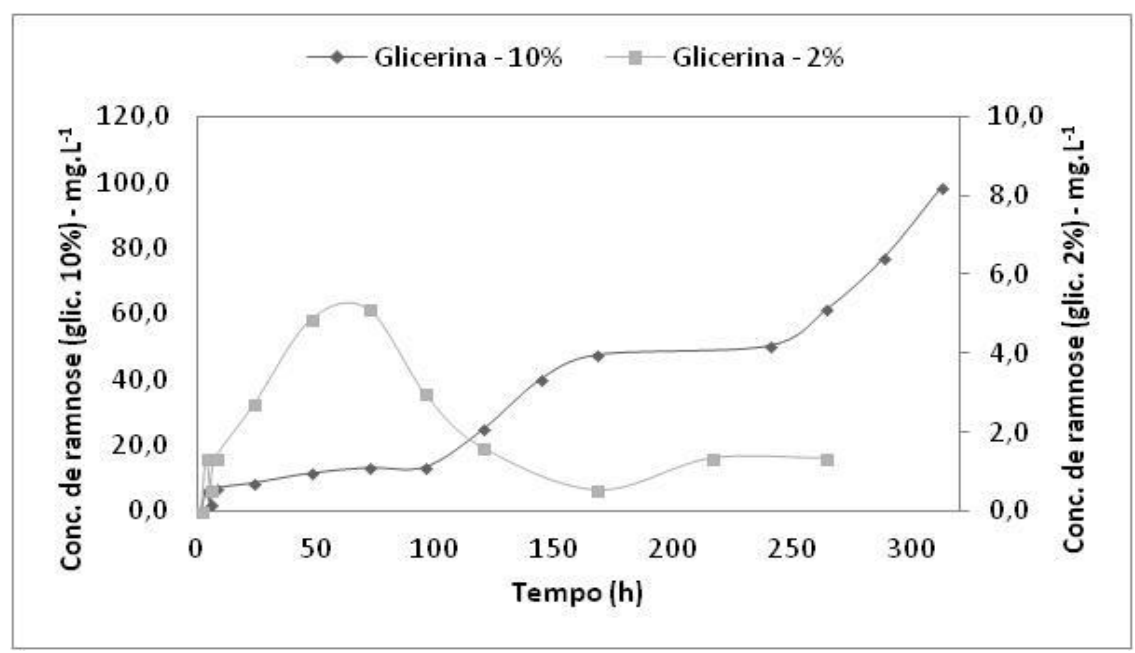

Figura 4 - Avaliação da produção de ramnose utilizando glicerina como fonte de carbono nas concentrações de $2 \%$ e $10 \%$. 
Como se pode observar na Figura 4, diferente do que ocorreu quanto foi empregada uma baixa concentração de carbono, o aumento da concentração do substrato permitiu uma elevada produção do biossurfactante, que atingiu um valor de $98,87 \mathrm{mg} . \mathrm{L}^{-1}$ de ramnose ao final do tempo de fermentação. Porém, esta ainda encontrava-se em fase de aumento da concentração, indicando que, caso a fermentação continuasse, poderia se conseguir valores mais elevados.

\subsection{Ensaios de biodegradação}

As Figuras 5 e 6 apresentam o percentual de Óleos \& Graxas durante o processo de biorremediação (bioaumentação e atenuação natural) do solo contaminado com óleo bruto e com diesel.

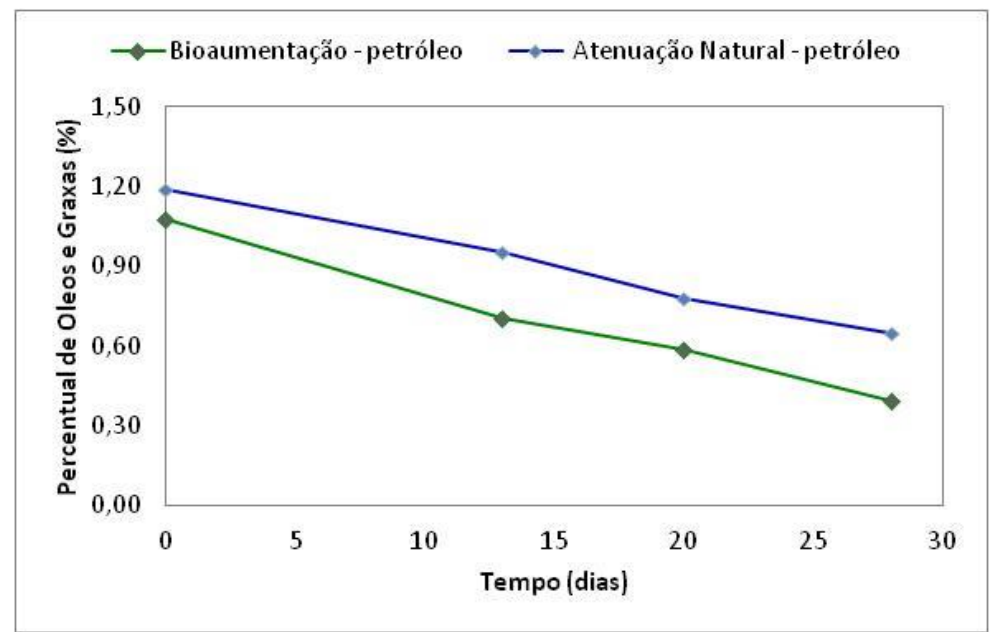

Figura 5 - Porcentagem de petróleo presente no solo.

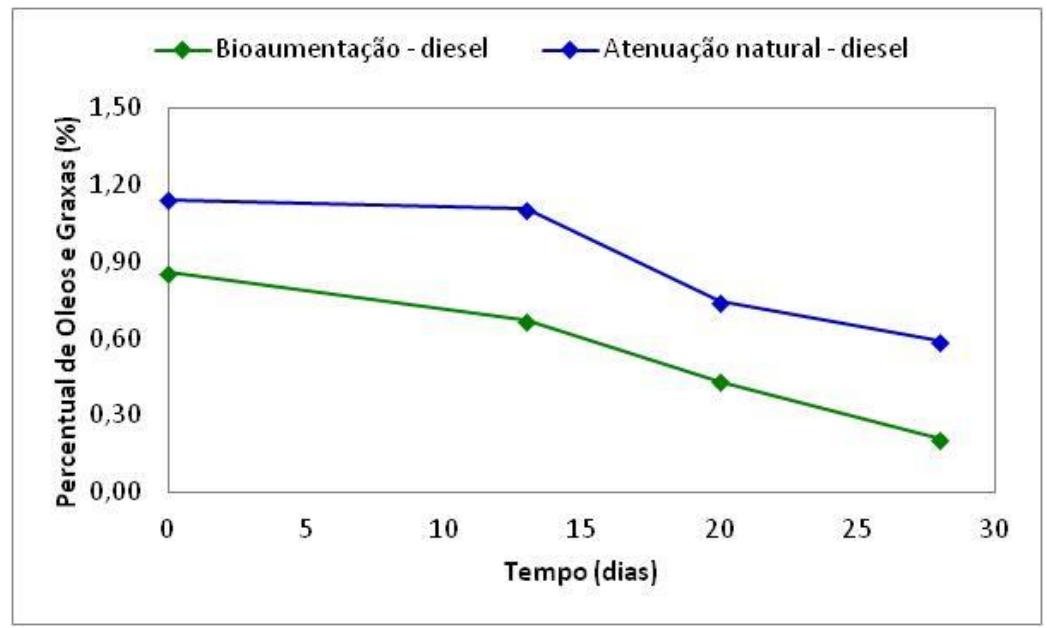

Figura 6 - Porcentagem de diesel presente no solo.

Na tabela 5 abaixo se encontram os resultados para a taxa de remoção para o período total de 
análise (28 dias).

Tabela 1 - Resultados da remoção de óleos e graxas.

\begin{tabular}{ccc}
\hline & \% de remoção de Óleos e Graxas (\% RO\&G) & \\
\hline Composto & Tipo de Biorremediação & \%RO\&G \\
Óleo bruto & Bioaumentação & $63,50 \%$ \\
Óleo bruto & Atenuação Natural & $45,36 \%$ \\
Diesel & Bioaumentação & $75,47 \%$ \\
Diesel & Atenuação Natural & $48,51 \%$ \\
\hline
\end{tabular}

Verifica-se na Tabela 1 que o diesel foi o composto mais facilmente removido, independentemente do processo de biorremediação usado. Sendo os resultados do processo de bioaumentação significativamente superiores, tanto para o óleo bruto como para o diesel.

O fato de o diesel apresentar melhores resultados, quando comparado ao óleo bruto, pode ser explicado por este apresentar estruturas orgânicas mais simples (hidrocarbonetos cuja cadeia contém de 10 a 50 átomos de carbono), mais facilmente biodegradáveis do que os hidrocarbonetos do óleo bruto (mistura complexa de hidrocarbonetos e de impurezas, como enxofre, nitrogênio, metais, oxigênio e outros).

\section{CONCLUSÕES}

A bactéria Pseudomona aeruginosa isolada neste estudo, apresentou capacidade de produzir ramnose com valores de 5,14 mg. $\mathrm{L}^{-1}$ e $98,87 \mathrm{mg} . \mathrm{L}^{-1}$, para concentrações e glicerina $2 \%$ e $10 \%$, respectivamente, indicando a capacidade produzir biossurfactante.

Ao testar a capacidade do microrganismo na remediação de solos contaminados, no ensaio de bioaumentação este apresentou remoções de 63,50\% (petróleo) e 75,41\% (diesel), mais elevadas que as remoções observadas na atenuação natural, $45,36 \%$ (petróleo) e $48,71 \%$ (diesel) indicando que os microrganismos adicionados ao meio contaminado utilizou os hidrocarbonetos presentes como fonte de carbono em 28 dias de avaliação.

\section{REFERÊNCIAS}

FONTES, G.C.; AMARAL, P.F.F.; COELHO, M.A.Z. Produção de biossurfactante por levedura. Quim. Nova, v.31, n. 8, p.2091-2099, 2008.

KRONEMBERGER, F.A; SANTA ANNA, L.M.M.; MENEZES, R.R.; FERNANDES, A.C.L.B.; BORGES, C.P.; FREIRE, D.M.G. Controle da Oxigenação na Produção de Biossurfactantes em Biorreator, SINAFERM, Curitiba-PR, 2007.

MOREIRA, F. M. S.; SIQUEIRA, J. O. Microbiologia e Bioquímica do Solo. Lavras: Ed. UFLA, 2002. 
PASUMARTHI, R.; CHANDRASAKARAN, S.; MUTNURI, S. Biodegradation of crude oil by Pseudomonas aeruginosa and Escherichia fergusonii isolated from the Goan coast. Marine Pollution Bulletin, 76, 276-282, 2013.

PEREIRA, L. T. C.; LEMOS, J. L. S. Degradação de hidrocarbonetos de petróleo por Aspergillus Niger e Penicillium Corylophilum. Disponível em: http://www.scielo.com.br/. Acesso em: out. 2013.

ROBERT. M.; MERCADÉ, M.E.; BOSH, M.P.; PARRA, J.L.; ESPUNY, M.J.; MANRESA, M. A.; GUINEA, J. Effect of the carbon source on biosurfactant production by Pseudomonas aeruginosa 44T1. Biotechnol. Lett., v.11, n.12, p. 871-874, 1989.

SOUZA, D. B.; BRITO, G. C. B.; VANCONCELOS, F. C. W.; BRAGA, L. C. Estudo de microorganismos presentes em uma área contaminada por gasolina comercial. Revista de estudos ambientais, Blumenau, v. 12, n. 2, p. 38-46, 2010.

ZANG, G.; WU, Y.; QIAN, X.; MENG, Q. Biodegradation of crude oil by Pseudomonas aeruginosa in the presence of rhamnolipids. Journal of Zhejiang University SCIENCE, Hangzhou, v.6B, n.8, p.725-730, 2005.

ZHANG, Y.; MILLER, R. M. Effect of a Pseudomonas rhamnolipid biosurfactant on cell hydrophobicity and biodegradation of octadecane. Applied and Environmental Microbiology, 60(6): 2101-2106, 1994. 